same course, and, as far as individual experience goes, bear testimony to its efficiency. It is not so objectionable to the little patient's friends as a blister, and is at the same time more manageable; and, from the extent of surface to which it is applied, decidedly more powerfully revulsive.

\section{REMOVAL OF RINGS FROM SWOLLEN FINGERS.}

By E. Garraway, Esq., Faversham.

THE following method of removing a ring from a swollen finger, I have reason to believe, is not so generally known as it deserves. Whence I derived the idea is out of my remembrance; but the claim of its origin certainly does not rest with me.

A patient, in whom I have just had recourse to it, was suffering from acute rheumatism. The fingers were swollen; and the wedding-ring and its keeper had become imbedded, causing no little pain, and considerable alarm at the prospect of having the rings filed or broken off. The mode of pro. ceeding is this. A reel of cotton is wound evenly round, beginning on the extremity of the finger and bringing each coil into close apposition with the preceeding, until the ring is reached. A needle is then threaded with the cotton, and passed under the ring, and the thread is carefully unwound from the finger. The ring follows each coil as it is successively urrolled, and by almost impercentible degrees is brought over the knuckle and removel. Care must be taken that the cotton is wound on evenly, particularly over the protuberant and swollen linuckle, or an entanglement will occur in the unwinding. A small curved needle will pass more readily under the ring than a straight one. The process requires time, care, faith, and patience; but the reward is ample in the gratitude of the suffering patient, the signet of whose marriage bond has been saved from destruction.

\section{Transartions of 迶randtres.}

\section{SOUTH-WESTERN BRANCH.} PRESIDENT'S ADDRESS.

By C. Radclyffe Hai.s, Mi.D., Torquay. [Delivered June 23rd, 1859.]

Gentlenen,-My first duty is the very pleasing one of giving you a hearty welcome, on the part of myself and my medical brethren of Torquay, and of assuring you how highly I esteem the honour of being appointed your president for the ensuing year. To most of those whorn I have the honour of addressing, the place in which we are met together needs no introduc tion, yet on one or two points I may be permitted to allude to it. If Turquay, from its modern origin, can offer none of the historical associations in which Exeter and Plymouth are rich, as pre-eminently a health-town its youth is a great advantoge. Free from all the disqualifications of age, it has grown up into its present size within the very recent period during which alone sanitary considerations, on a large scale, have been deemed worthy of formal attention. Its principal attractions of situation, climate, and beauty, are, of course, as old as the hills over which its buildings spread; but its urban advantages are only just completed. Torquay ought now to be the model town of England, as regards sanitary arrangements. I am not sure that it is not so. Fresh air, pure water, effective drainage, all in abundance, constitute almost ail which public bodies can do to render their town healthy. Looking at the geology and general aspect of 'Torquay, a stranger would suppose it impossible for it to be otherwise than well drained by nature. Bu man has great power to thwart the beneficence of nature; and when cholera visited this place in 1849 , it pointed out accurately, as with a black line, where the drainage was imperfect. Under the government of our Local Board of Health, which, through good report and evil report, has proved of immense service to the town, all this is now rectified.

Effective drainage is impossible without an ample supply of water. From the absense of any large source of fresh water in the immediate neighbourhood, it has been necessary to obtain it from a distance of fourteen miles, on the margin of Dartmoor, at a cost to the town of between $£ 40,000$ and $£ 50,000$ This water is very pure, having trickled merely through the granite of Dartmoor; and, whether from the disintegration of the granite having given to it some minute portion of alkali, or from some other cause, it is found to be actually softer than the rain-water collected here. Heretofore we have been chary of saying much in favour of Torquay as a place of resort for patients who suffer from chronic affections of the kidneys, because, however useful in such disorders it may be to reside in a mild climate, which promotes the action of the skin, yet, as a rule, a hard calcareous water does not suit reral affections; and our spring water is very hard. Like water of this kind clsewhere, it is bright, clear, and sparkling; pleasant to the taste, and possibly not without its virtues for those whose bodies betray a want of lime: certainly not without its chemical potency out of the body; for, but for its presence, we must have suffered from lead-poisoning on a large scale. I suppose every house that has a pump is supplied with spring water through lead pipes; yet we never see any instance of lead poisoning from this cause, either slight or severe. And this is not because the water does not act upon the lead, since we find that the pipes are coated on their interior, and eventually, in places, eaten through in a worm-eaten fashion. Yet reagents shew no trace of lead in the water. Evidently the water forms an insoluble compound with the lead, which is precipitated in the shape of carbonate and hydrated oxide. Excepting water so impure, from contamination with drains, as to contain alkaline nitrates and chlorides in solution, as a general rule we know that the purer and softer the water, the more dangerous for lead; and, consequently, the immunity we have hitherto enjoyed must not, as a matter of course, be taken for granted to apply to the new water. As this, however, requires a new and distinct service, and the custom is to use iron pipes for it, the question will not be put to the test by the public. Experimentally, though it acts rather too freely upon iron, I find this new water does not dissolve lead. Torquay can now boast not only of good water in abundance, both hard and soft,- and so suit both ricketty children and gouty parents, - but it also possesses, for the external employment of water, whether fresh or sea, perhaps the finest baths in the kingdom. Erected at a cost of nearly $\$ 10,000$ these excellent baths-as I think the quict splendour of this saloon, in which, by the liberality of the directors, we are now sitting, will testify-reflect great credit on the public spirit of those private individuals who have thus deserved so well of their town.

Of the winter climate of Torquay, it is unnecessary to say one word; but respecting its summer climate, a passing remark may not be misplaced. Mr. Vivian has proved beyond all question that figures substantiate the coolness of our summer climate. Yet no one believes him ;-excepting those only who have stayed at Torquay during the summer. 'The air is always a soft air, but never an over hot air; you do not find your lips parched or your mouth dry. Of course, the direct heat of the sun in this clear atmosphere is often considerable; but on the hills, or in open places; in summer the air is soft and fresh. "I know nothing about the mildness of Torquay in the winter, because I hare never been here in the winter," said a Cheshire gentleman to me, "but I know this that it is the coolest place in England in the summer"! And, to a certain extent, it ought to be Being almost a peninsula, the same modifying influence of the sea which causes its winter-mildness, must render it cool in summer. The sea, being a worse conductor of heat than the land, cools less in winter, and heats less in summer and accordingly, the sea-breezes warm the air over the neigh bouring coast in winter, and cool the air in summer. Moreover, the adjoining land being thus cooled down by the sea air every night in summer, cannot accumulate heat during the persistence of hot dry weather as it does in inland places.

Having adverted to our obligations to Mr. Vivian on the subject of meteorology, I cannot resist referring to his recent work in editin at the cost of no inconsiderable labour, $\mathrm{Mc}$ Enery's Cavern Researches, in which the geologist will find the most interesting information respecting our world-wide celebrated Kent's Cavern, and Ossiferous Caves in general-such, for example, as the newly discovered one at Brixham, now in process of investigation under the superintendence of $\mathrm{Mr}$. Pengelly, the 'Torquay geologist par excellence.

Torquay possesses three medical institutions. The Torbay Infirmary and Dispensary, which does all that the most ad mirable institution of this kind can, has a staff of three phy. sicians, three surgeons, and a House-Surgeon. The honorary officers of this institution have here, as elsewhere, the privilege of bestowing their constant charity in deeds of active exertion for the benefit of the sick and needy;-a kind of charity which in actual benefit so far transcends the mere giving of 